\title{
Effects of Hormone Replacement Therapy on Insulin Resistance and Platelet Function Tests
}

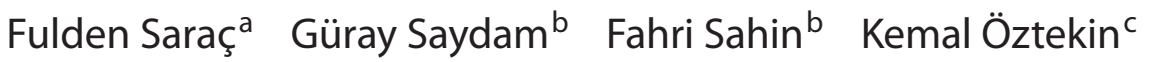 \\ Fusun Saygılı $^{\mathrm{a}}$ Mehmet Tüzün ${ }^{\mathrm{a}}$ Candeger Yılmaz $^{\mathrm{a}}$ \\ Departments of a Endocrinology and Metabolism, ${ }^{b}$ Hematology and ${ }^{c}$ Gynecology and Obstetrics, \\ Ege University Hospital, Izmir, Turkey
}

\section{Key Words}

Insulin resistance $\cdot$ Platelet function $\cdot$ Hormone

replacement $\cdot$ Postmenopausal women

\begin{abstract}
Objectives: The aim of this study was to evaluate measures of insulin resistance and platelet function in postmenopausal women with oral or transdermal hormone replacement therapy (HRT). Subjects and Methods: Eighty women divided into four groups of 20 each were enrolled in the study. Group 1: postmenopausal hysterectomized women who received only transdermal estradiol $\left(13.9 \mathrm{mg} / 12.5 \mathrm{~cm}^{2}\right)$; group 2: women with intact uterus who were treated with estrogen-progestin combination (HRT); group 3: postmenopausal women who were treated with the selective estrogen receptor modulator tibolone, and group 4: women who were not taking any drugs for HRT were chosen as a control group (group 4). Results: In group 2, homeostasis model assessment of insulin resistance and fasting insulin levels were 2.90 \pm 0.37 and $9.3 \pm 3.0 \mu \mathrm{U} / \mathrm{ml}$, respectively, prior to administration of HRT. These levels were reduced to $1.91 \pm 0.41(p=$ $0.001)$ and $7.1 \pm 2.7 \mu \mathrm{U} / \mathrm{ml}(p=0.002)$, respectively, after drug therapy. Mean levels of high-sensitivity C-reactive protein (hsCRP) were decreased with HRT only in group 2 ( $p=$ 0.002 ). No changes for biochemical and hematological pa-
\end{abstract}

rameters were observed in the other groups. Platelet function tests showed no differences after HRT in any group. Conclusions: Estrogen-progestin combination HRT decreased measures of insulin resistance and hsCRP levels, but had no effect on platelet function tests in postmenopausal women.

Copyright $\odot 2008$ S. Karger AG, Basel

\section{Introduction}

Menopause is associated with an increased risk of cardiovascular disease. Some of this risk may be related to changes in body composition, body fat distribution, and insulin sensitivity. Also, after menopause, climacteric women whose estradiol status is low have a decreased platelet activation status compared with premenopausal women [1]. Insulin sensitivity decreases after menopause, thus increasing the risk of diabetes and cardiovascular disease $[1,2]$. Studies evaluating the effect of hormone replacement therapy (HRT) on glucose disposal in postmenopausal women have led to mixed results, depending on the regimen used [3-5]. However, studies evaluating HRT with combined estrogen and continuous progestin demonstrated a decrease in insulin sensitivity [6]. 
In a previous study, Bar et al. [7] suggested that patients receiving replacement regimens consisting of estrogen opposed by progestogen or progestogen alone showed nonsignificant changes in platelet aggregation and release. Recently, Wallen et al. [8] showed that there was no effect of oral HRT on platelet function in postmenopausal women with coronary artery disease.

The aims of this study were to the evaluate (a) insulin resistance, (b) platelet function tests (fibrinogen), and (c) high-sensitivity C-reactive protein (hsCRP) levels in postmenopausal women using oral or transdermal HRT.

\section{Subjects and Methods}

Eighty postmenopausal women ranging in age from 40 to 60 (mean $52 \pm 4.5$ ) years were enrolled in the 6-month study which was performed at the outpatient clinic of the Department of $\mathrm{Ob}$ stetrics and Gynecology. Subjects with any underlying disease (cardiovascular, self-reported infectious, diabetes mellitus, hyperthyroidism, hypothyroidism, or autoimmune diseases) or on medication likely to influence the results (such as aspirin, drugs affecting the immune system, statins) were not eligible for the study. Although cigarette smoking and alcohol consumption were defined as exclusion criteria for the study, only alcohol consumption of more than a glass of wine per day was accepted as an exclusion criterion because smoking is a widespread habit in Turkey. A change in smoking pattern before and after treatment was also defined as an exclusion criterion. All participants were normotensive and had been amenorrheic for 12 months to 5 years. Postmenopausal status was confirmed by follicle-stimulating hormone concentrations $>20 \mathrm{IU} / 1$ and estradiol concentrations $<150 \mathrm{pmol} / \mathrm{l}$. None of the women had received HRT for at least 3 months before entering the study.

The study protocol was approved by the Ethics Committee of Ege University. All subjects gave written informed consent before entering the study. Study patients were classified into four equal groups of 20 each. Group 1: postmenopausal hysterectomized women who received only transdermal estradiol $(13.9 \mathrm{mg} / 12.5$ $\mathrm{cm}^{2}$ ); group 2: women with intact uterus were treated with estrogen-progestin combination, estrogen (estradiol 17-valerate, $2 \mathrm{mg}$ ) was given alone in the first half of the cycle and progestin (cyproterone acetate, $1 \mathrm{mg}$ ) was added in the second half; group 3: postmenopausal women who were treated with tibolone, and group 4, the control group: women who were not taking any drug for HRT. All patients were evaluated before and after 6 months for the effect of HRT use. Physical and laboratory examinations were performed in all the patients. No patient was withdrawn from the study.

Clinical examination and laboratory blood analyses were carried out, anthropometric analyses before and after 6 months of treatment. Serum concentrations of glucose, triglyceride, total and high-density lipoprotein (HDL cholesterol) were determined by enzymatic procedures. Serum insulin levels were measured by chemiluminescence. Plasma levels of hsCRP and fibrinogen were determined by immunoturbidimetric assay and a coagulation method, respectively. Measurements of insulin resistance were obtained using the homeostasis model assessment [HOMA-IR; $\mathrm{IR}=$ fasting glucose $(\mathrm{mg} / \mathrm{dl}) \times$ fasting insulin $(\mu \mathrm{U} / \mathrm{ml}) / 22.5]$ [9]

Epinephrine, ADP, collagen (soluble calfskin), and other nonspecific reagents were purchased from Bio/Data Corp. (Horsham, Pa., USA). Platelet function tests were performed with a platelet aggregation profiler (Bio/Data Corp.). Human platelet-rich plasma (PRP) was prepared according to a previously published method [10]. Venous blood was freshly drawn from patients who had not ingested any drugs that may have had an effect on platelet function during the last 4 weeks. To obtain PRP, the blood was immediately mixed with $3.8 \%$ citrate $(9: 1 \mathrm{vol} / \mathrm{vol})$ and then centrifuged at $150 \mathrm{~g}$ for $15 \mathrm{~min}$ at room temperature. The top-layer PRP was collected by using a plastic Pasteur pipette and placed in a clean plastic centrifuge tube. The remaining red cells and buffy coat were centrifuged at $1,500 \mathrm{~g}$ for $15 \mathrm{~min}$ to obtain autologous platelet-poor plasma. In vitro platelet aggregation was monitored simultaneously using a Lumi-Aggregometer (Bio/Data Corp.) according to the manufacturers' instructions as previously described [11]. Measurements were made for ADP, collagen, and epinephrine; the final concentrations were $10 \mu \mathrm{mol}, 2 \mu \mathrm{g} / \mathrm{l}$, and 10 $\mu \mathrm{mol}$, respectively. The aggregation responses were quantified as the maximum extent of aggregation, calculated by the maximum change in light transmission, and expressed as a percentage, considering the difference between light transmission for the platelet suspension and suspension buffer as a value of $100 \%$ (normal values for collagen: 60-90\%; epinephrine: 70-90\%; ADP: 70-90\%).

\section{Statistics}

Statistical analysis was performed with SPSS for Windows (13.0) packaged software. Numerical variables were summarized with mean $\pm \mathrm{SD}$. Baseline data were compared using one-way analysis of variance (ANOVA). Change in a parameter was calculated as the value obtained at the end of treatment subtracted from the value obtained at the beginning of the intervention (baseline). ANOVA was also used to assess within- and between-group significance when a $\mathrm{p}$ value was significant; a one-sample Student $t$ test was used to compare values before and after treatment, and two-sample t tests were used for between-group comparisons.

\section{Results}

Demographic characteristics of all groups are shown in table 1. Mean values of body mass index in groups 1,2, 3 , and 4 were $27.53 \pm 4.9,25.93 \pm 6.5,24.32 \pm 4.9$, and $25.30 \pm 2.5 \mathrm{~kg} / \mathrm{m}^{2}$, respectively. Mean levels of systolic blood pressure in groups 1, 2, 3, and 4 were $125.83 \pm 19.1$, $121.39 \pm 21.7,128.9 \pm 21.1$, and $113.7 \pm 10.1 \mathrm{~mm} \mathrm{Hg}$, respectively, before drug therapy. Mean levels of diastolic blood pressure in groups $1,2,3$, and 4 were $67.45 \pm 26.5$, $60.90 \pm 16.90,71.4 \pm 20.2$, and $69.1 \pm 17.2 \mathrm{~mm} \mathrm{Hg}$, respectively, at baseline. No significant differences after 6 months were observed between all groups with regard to anthropometric data (table 1).

Biochemical and hematological parameters of the groups are presented in table 2 . In group 2, the initial 
Table 1. Mean anthropometric data before and after treatment

\begin{tabular}{|c|c|c|c|c|}
\hline & Group 1 & Group 2 & Group 3 & Group 4 \\
\hline Age & $50.7 \pm 3.6$ & $49.2 \pm 1.6$ & $52.7 \pm 1.6$ & $50.6 \pm 3.6$ \\
\hline Menopause age & $5.1 \pm 0.6$ & $4.34 \pm 0.89$ & $4.7 \pm 1.6$ & $5.6 \pm 0.76$ \\
\hline \multicolumn{5}{|c|}{ Body mass index, $\mathrm{kg} / \mathrm{m}^{2}$} \\
\hline Before drug & $27.53 \pm 4.9$ & $25.93 \pm 6.5$ & $24.32 \pm 4.9$ & $25.30 \pm 2.5$ \\
\hline After drug & $26.03 \pm 6.5$ & $26.82 \pm 3.0$ & $25.11 \pm 4.8$ & $25.75 \pm 6.5$ \\
\hline $\mathrm{p}$ & NS & NS & NS & NS \\
\hline \multicolumn{5}{|l|}{ Weight, kg } \\
\hline Before drug & $75.83 \pm 19.5$ & $76.06 \pm 11.7$ & $70.99 \pm 19.1$ & $80.23 \pm 10.1$ \\
\hline After drug & $70.55 \pm 26.5$ & $77.50=$ & 70.78 & $80.96 \pm 16.8$ \\
\hline $\mathrm{p}$ & NS & NS & NS & NS \\
\hline \multicolumn{5}{|l|}{ Waist, $\mathrm{cm}$} \\
\hline Before drug & $90.15 \pm 11.9$ & $95.8 \pm 16.7$ & $88.65 \pm 13.1$ & $93.7 \pm 10.6$ \\
\hline After drug & $89.50 \pm 14.8$ & $90.23 \pm 16.0$ & $89.33 \pm 12.5$ & $90.16 \pm 11.0$ \\
\hline $\mathrm{p}$ & NS & NS & NS & NS \\
\hline \multicolumn{5}{|c|}{ Systolic blood pressure } \\
\hline Before drug & $125.83 \pm 19.1$ & $121.39 \pm 21.7$ & $128.9 \pm 21.1$ & $113.7 \pm 10.1$ \\
\hline After drug & $120.50 \pm 26.5$ & $120.67 \pm 30.4$ & $117.43 \pm 30.7$ & $70.50 \pm 6.58$ \\
\hline $\mathrm{p}$ & NS & NS & NS & NS \\
\hline \multicolumn{5}{|c|}{ Diastolic blood pressure } \\
\hline Before drug & $67.45 \pm 26.5$ & $60.90 \pm 16.9$ & $71.4 \pm 20.2$ & $69.1 \pm 17.2$ \\
\hline After drug & $70.31 \pm 16.1$ & $63.45 \pm 21.8$ & $70.8 \pm 11.8$ & $70.10 \pm 16.8$ \\
\hline $\mathrm{p}$ & NS & NS & NS & NS \\
\hline \multicolumn{5}{|c|}{ Cigarettes per day } \\
\hline Before drug & $1.0 \pm 0.01$ & $1.1 \pm 0.03$ & $1.2 \pm 0.02$ & $0.8 \pm 0.01$ \\
\hline After drug & $1.1 \pm 0.01$ & $1.3 \pm 0.01$ & $1.1 \pm 0.00$ & $0.7 \pm 0.01$ \\
\hline $\mathrm{p}$ & NS & NS & NS & NS \\
\hline
\end{tabular}

Group 1 = Transdermal estradiol; group 2 = estradiol 17-valerate/cyproterone acetate; group $3=$ tibolone; group $4=$ no drug. $\mathrm{NS}=$ Nonsignificant.

HOMA-IR and fasting insulin levels were $2.90 \pm 0.37$ and $9.3 \pm 3.0 \mu \mathrm{U} / \mathrm{ml}$, respectively. HOMA-IR and fasting insulin were reduced to $1.91 \pm 0.41(\mathrm{p}=0.001)$ and $7.1 \pm$ $2.7 \mu \mathrm{U} / \mathrm{ml}(\mathrm{p}=0.002)$, respectively, after HRT. Mean levels of fibrinogen of all groups were not changed with treatment. However, the mean level of hsCRP was significantly reduced after HRT in group 2 .

Platelet function tests did not reveal any statistically significant changes after HRT (table 3).

\section{Discussion}

Adverse thrombolytic events increase following menopause. HRT may suppress procoagulant and inflammatory markers of endothelial cells $[12,13]$. There may also be a direct effect of combined HRT on platelet function in vivo. Indeed functional estrogen receptors are present in megakaryocytes and in blood platelets, as shown in vitro [14]. To our knowledge, no progestagen receptors have been found in blood platelets or their precursors. Platelet activation and activity in humans are accompa-
Table 2. Mean biochemical tests before and after treatment with drugs

\begin{tabular}{|c|c|c|c|c|}
\hline & Group 1 & Group 2 & Group 3 & Group 4 \\
\hline \multicolumn{5}{|c|}{ Fasting glucose, $\mathrm{mg} / \mathrm{dl}$} \\
\hline Before drug & $92.1 \pm 11.4$ & $89.6 \pm 9.9$ & $93.4 \pm 13.9$ & $90.2 \pm 9.5$ \\
\hline After drug & $90.8 \pm 17.9$ & $92.1 \pm 10.5$ & $92.1 \pm 16.6$ & $92.1 \pm 10.1$ \\
\hline $\mathrm{p}$ & NS & NS & NS & NS \\
\hline \multicolumn{5}{|c|}{ Fasting insulin, $\mu \mathrm{U} / \mathrm{ml}$} \\
\hline Before drug & $10.5 \pm 2.6$ & $9.3 \pm 3.0$ & $9.6 \pm 6.6$ & $7.1 \pm 1.1$ \\
\hline After drug & $9.9 \pm 1.9$ & $7.1 \pm 2.7$ & $8.4 \pm 1.3$ & $6.9 \pm 1.9$ \\
\hline $\mathrm{p}$ & NS & 0.002 & NS & NS \\
\hline \multicolumn{5}{|l|}{ HOMA-IR } \\
\hline Before drug & $2.52 \pm 0.71$ & $2.90 \pm 0.37$ & $2.06 \pm 0.71$ & $1.68 \pm 0.37$ \\
\hline After drug & $2.4 \pm 0.95$ & $1.91 \pm 0.41$ & $1.91 \pm 0.95$ & $1.87 \pm 10.95$ \\
\hline $\mathrm{p}$ & NS & 0.001 & NS & NS \\
\hline \multicolumn{5}{|c|}{ Total cholesterol, mg/dl } \\
\hline Before drug & $209.1 \pm 21.7$ & $201.0 \pm 31.7$ & $191.0 \pm 22.8$ & $198.8 \pm 40.9$ \\
\hline After drug & $199.1 \pm 20.9$ & $200.1 \pm 30.9$ & $198.9 \pm 20.9$ & $192.1 \pm 33.5$ \\
\hline $\mathrm{p}$ & NS & NS & NS & NS \\
\hline \multicolumn{5}{|c|}{ LDL cholesterol, mg/dl } \\
\hline Before drug & $138.8 \pm 29.3$ & $141.7 \pm 39.3$ & $133.2 \pm 29.5$ & $138.2 \pm 23.5$ \\
\hline After drug & $132 \pm 20.9$ & $139.9 \pm 30.7$ & $130.5 \pm 23.4$ & $133.7 \pm 29.8$ \\
\hline $\mathrm{p}$ & NS & NS & NS & NS \\
\hline \multicolumn{5}{|c|}{ HDL cholesterol, mg/dl } \\
\hline Before drug & $44.5 \pm 6.1$ & $39.5 \pm 9.8$ & $41.3 \pm 8.1$ & $40.5 \pm 4.5$ \\
\hline After drug & $39.2 \pm 9.5$ & $40.7 \pm 4.3$ & $39.2 \pm 6.1$ & $38.1 \pm 9.4$ \\
\hline $\mathrm{p}$ & NS & NS & NS & NS \\
\hline \multicolumn{5}{|c|}{ Triglyceride, mg/dl } \\
\hline Before drug & $165.9 \pm 30.4$ & $155.4 \pm 31.4$ & $140.3 \pm 43.6$ & $148.1 \pm 48.1$ \\
\hline After drug & $160.8 \pm 29.5$ & $150.2 \pm 29.8$ & $163.2 \pm 22.4$ & $154.2 \pm 25.3$ \\
\hline $\mathrm{p}$ & NS & NS & NS & NS \\
\hline \multicolumn{5}{|c|}{ Fibrinogen, mg/dl } \\
\hline Before drug & $375.4 \pm 49.6$ & $304.0 \pm 40.1$ & $375.4 \pm 49.6$ & $304.0 \pm 35.5$ \\
\hline After drug & $380.2 \pm 46.9$ & $333.2 \pm 29.5$ & $380.7 \pm 33.2$ & $303.2 \pm 29.1$ \\
\hline $\mathrm{p}$ & NS & NS & NS & NS \\
\hline \multicolumn{5}{|l|}{ hsCRP, mg/dl } \\
\hline Before drug & $0.25 \pm 0.01$ & $0.30 \pm 0.19$ & $0.27 \pm 0.11$ & $0.26 \pm 0.19$ \\
\hline After drug & $0.26 \pm 0.02$ & $0.27 \pm 0.02$ & $0.26 \pm 0.001$ & $0.27 \pm 0.029$ \\
\hline $\mathrm{p}$ & NS & 0.002 & NS & NS \\
\hline \multicolumn{5}{|l|}{ Hematocrit, \% } \\
\hline Before drug & $35.90 \pm 6.3$ & $34.76 \pm 3.4$ & $33.3 \pm 4.5$ & $34.7 \pm 4.7$ \\
\hline After drug & $33.21 \pm 5.5$ & $33.76 \pm 4.8$ & $35.8 \pm 3.8$ & $33.1 \pm 3.5$ \\
\hline $\mathrm{p}$ & NS & NS & NS & NS \\
\hline \multicolumn{5}{|c|}{ Leukocytes, $\times 10^{3} / \mathrm{mm}^{3}$} \\
\hline Before drug & $8.5 \pm 1.8$ & $9.8 \pm 1.7$ & $7.8 \pm 1.4$ & $9.9 \pm 1.5$ \\
\hline After drug & $8.2 \pm 2.5$ & $9.2 \pm 1.1$ & $7.2 \pm 0.9$ & $8.8 \pm 1.1$ \\
\hline $\mathrm{n}$ & NS & NS & NS & NS \\
\hline \multicolumn{5}{|c|}{ Platelets, $\times 10^{3} / \mathrm{mm}^{3}$} \\
\hline Before drug & $396.5 \pm 47.4$ & $348.3 \pm 51.4$ & $409.3 \pm 40.3$ & $416.7 \pm 48.5$ \\
\hline After drug & $333.2 \pm 39.5$ & $363.2 \pm 49.1$ & $413.2 \pm 59.7$ & $433.8 \pm 39.8$ \\
\hline $\mathrm{p}$ & NS & NS & NS & NS \\
\hline
\end{tabular}

Group 1 = Transdermal estradiol; group 2 = estradiol 17-valerate/cyproterone acetate; group $3=$ tibolone; group $4=$ no drug. $\mathrm{NS}=$ Nonsignificant.

nied by changes in the antigenic repertoire on the platelet surface. In women treated with $17 \beta$-estradiol only, there was also evidence of increased platelet activation [15]. Platelet alterations have been reported in response to HRT by measuring platelet aggregation, mean platelet 
Table 3. Platelet aggregation tests (\%) before and after treatment

\begin{tabular}{lllll}
\hline $\begin{array}{l}\text { Platelet aggregation } \\
\text { tests }\end{array}$ & Group 1 & Group 2 & Group 3 & Group 4 \\
\hline ADP & & & & \\
$\quad \begin{array}{llll}\text { Before drug } \\
\text { After drug }\end{array}$ & $72.10 \pm 19.7$ & $69.13 \pm 8.1$ & $70.13 \pm 15.1$ & $67.07 \pm 8.9$ \\
p & NS & NS & NS & NS \\
Epinephrine & & & & \\
$\quad \begin{array}{l}\text { Before drug } \\
\text { After drug }\end{array}$ & $65.43 \pm 11.5$ & $66.21 \pm 9.8$ & $66.31 \pm 10.1$ & $66.21 \pm 9.8$ \\
p & NS & NS & NS & NS \\
Collagen & & & & \\
Before drug & $70.16 \pm 14.8$ & $64.01 \pm 9.9$ & $71.89 \pm 13.9$ & $71.99 \pm 14.9$ \\
After drug & $69.56 \pm 11.3$ & $65.85 \pm 10.8$ & $69.17 \pm 12.6$ & $70.79 \pm 10.8$ \\
p & NS & NS & NS & NS \\
Ristostetin & & & & \\
Before drug & $65.70 \pm 12.4$ & $69.23 \pm 13.1$ & $70.13 \pm 15.1$ & $65.43 \pm 10.5$ \\
After drug & $64.94 \pm 8.3$ & $68.71 \pm 10.3$ & $69.11 \pm 9.7$ & $64.14 \pm 9.3$ \\
p & NS & NS & NS & NS \\
\hline
\end{tabular}

Group 1 = Transdermal estradiol; group 2 = estradiol 17-valerate/cyproterone acetate; group 3 = tibolone; group $4=$ no drug. NS = Nonsignificant.

volume, platelet membrane fatty acid composition or urinary excretion of thromboxane $\mathrm{B}_{2}$ [16].

There are important differences between HRT preparations with regard to type and dose of estrogen, type of combination progestin and dose of estrogen, type of combination progestin and route of administration $[7,17,18]$. It has been demonstrated that HRT increases plasma concentrations of CRP [7]. Rossi et al. [17] reported that the progestin component of HRT significantly attenuated the estrogen-induced increase in CRP serum concentrations. Lakoski et al. [18] suggested that transdermal estrogen did not produce elevation in levels of CRP alone or with the addition of progestins. In contrast to the transdermal route, oral estradiol increased serum CRP. However, in one clinical trial medroxyprogesterone acetate attenuated the increase in CRP induced by estrogens in a dosedependent manner [3], while another study showed that the progestins were able to influence the estrogen-induced rise in CRP [4]. The elevation of CRP could compromise the beneficial effects of HRT, and progestins seem to be able to attenuate this effect [4]. In contrast to these previous reports, our study showed that hsCRP was reduced only in estrogen + progestin HRT (group 2). Fibrinogen increased after menopause in healthy women. Some authors have found a significant decrease in fibrinogen after HRT, but others have not [13]. In our study, neither route of HRT influenced plasma fibrinogen levels.
Postmenopausal women are at increased risk of diabetes. Stojanovic et al. [19] suggested that transdermal estradiol with or without dydrogesterone in women with type 2 diabetes did not adversely affect any of the measured markers of cardiovascular risk in these women. There was a significant decrease in HbAlc, total cholesterol and LDL cholesterol at 6 months in women receiving HRT. Other risk indicators such as HDL cholesterol, triglyceride, hsCRP, and fibrinogen were not changed as previously reported [19]. Likewise, a significant increase in fasting glucose was not seen in the women treated with combined conjugated equine estrogens and medroxyprogesterone acetate, suggesting a beneficial effect of HRT on fasting glucose [20]. In our study, mean fasting glucose levels were unchanged in any of the study groups. However, mean HOMA-IR level of patients treated with estradiol 17-valerate/cyproterone acetate was statistically significantly decreased but not in other groups.

If the loss of ovarian function reduces insulin sensitivity, it is plausible that HRT would improve insulin sensitivity in postmenopausal women. Contrary to this hypothesis, Sites et al. [21] found that oral combined conjugated estrogens and medroxyprogesterone acetate decreased insulin sensitivity in postmenopausal women. Perera et al. [22] previously demonstrated a neutral effect on insulin sensitivity of transdermal estradiol in combination with oral norethisterone acetate in women with type 2 diabetes without any evidence of an adverse effect on lipid metabolism or inflammation. Other investigators [23] have reported beneficial effects of oral unopposed estradiol $(2 \mathrm{mg})$ on glucose metabolism in these women. In a short-term study of postmenopausal women with metabolic syndrome, there was a statistically significant worsening of insulin resistance markers after estradiol therapy, including an increase in baseline insulin, and an increase in HOMA. However, transdermal estradiol had minimal effects on insulin resistance [24]. In our study, we investigated the effects of HRT on HOMA-IR in metabolically normal postmenopausal women. We observed a statistically significant decrease in the mean levels of fasting insulin, and HOMA-IR was significantly decreased with estrogen-progestin combination HRT.

\section{Conclusion}

Estrogen-progestin combination therapy in postmenopausal women affects insulin resistance and hsCRP levels but not platelet function tests. 


\section{References}

1 Goodrow GJ, L'Hommedieu GD, Gannon B, Sites CK: Predictors of worsening insulin sensitivity in postmenopausal women. Am J Obstet Gynecol 2006;194:355-361.

$>2$ Cooper BC, Burger NZ, Toth MJ, Cushman $\mathrm{M}$, Sites CK: Insulin resistance with hormone replacement therapy: associations with markers of inflammation and adiposity. Am J Obstet Gynecol 2007;196:123.e1123.e7.

-3 Van Baal WM, Kenemans P, van der Mooren MJ, Kessel H, Emeis JJ, Stehouwer CD: Increased C-reactive protein levels during short-term hormone replacement therapy in healthy postmenopausal women. Thromb Haemost 1999;81:925-928.

-4 Wakatsuki A, Okatani N, Ikenoue N, Fukaya T: Effect of medroxyprogesterone acetate on vascular inflammatory markers in postmenopausal women receiving estrogen. Circulation 2002;105:1436-1439.

$\checkmark 5$ Rossi R, Bursi F, Veronesi B, Cagnacci A, Modena M: Effects of progestins on estrogen-induced increase in C-reactive protein in postmenopausal women. Maturitas 2004; 49:315-320.

-6 Aldrighi JM, Oliveira RL, D’Amico E, Rocha TR, Gebara OE, Rosano GM, Ramires JA: Platelet activation status decreases after menopause. Gynecol Endocrinol 2005;20: 249-257.

$>7$ Bar J, Tepper R, Fuchs J, Pardo Y, Goldberger $\mathrm{S}$, Ovadia J: The effect of estrogen replacement therapy on platelet aggregation and adenosine triphosphate release in postmenopausal women. Obstet Gynecol 1993;81:261264.

$>8$ Wallen H, Li N, Berg M, Landgren BM, Gustafsson S, Hjemdahl P: No effect of oral hormone replacement therapy on platelet function in postmenopausal women with coronary artery disease. Thromb Haemost 2006;96:862-863. $\checkmark 9$ Matthews DR, Hosker JP, Rudenski AS, Naylor BA, Treacher DF, Turner RC: Homeostasis model assessment: insulin resistance and ß-cell function from fasting plasma glucose and insulin concentration in men. Diabetologia 1985;28:412-419.

10 Nakahashi TK, Kambayashi J, Nakamura T, Le SN, Yoshitake M, Tendon NN, Sun B: Platelets in nonresponders to epinephrine stimulation showed reduced response to ADP. Thromb Res 2001;104:127-135.

11 Toyoda H, Nakai K, Omay SB, Shima H, Nagao M, Shiku H, Nishikawa M: Differential association of protein Se/Thr phosphatase types 1 and $2 \mathrm{~A}$ with the cytoskeleton upon platelet activation. Thromb Haemost 1996; 76:1053-1062.

12 Wakatsuki A, Okatani N, Ikenoue N, Fukaya T: Effect of medroxyprogesterone acetate on vascular inflammatory markers in postmenopausal women receiving estrogen. Circulation 2002;105:1436-1439.

13 Lindoff C, Peterson F, Lecander I, Martinsson G, Åstedt B: Transdermal estrogen replacement therapy: beneficial effects on hemostatic risk factors for cardiovascular disease. Maturitas 1996;24:43-50.

14 Chang WC, Nakao J, Orimo H, Tai HH, Murota SI: Stimulation of 12-lipoxgenase activity in rat platelets by 17 beta-estradiol. Biochem Pharmacol 1982;31:2633-2638.

15 Khetwat G, Farday N, Nealen MI, Vijayan KV, Bolton E, Noga SJ, Bray PF: Human megakaryocytes and platelets contain the estrogen receptor beta and androgen receptor (AR): testosterone regulates AR expression. Blood 2000;95:2289-2296.

16 Ridker PM, Hennekens CH, Rifai N, Buring JE, Manson JE: Hormone replacement therapy and increased plasma concentration of C-reactive protein. Circulation 1999;10:713716.

17 Rossi R, Bursi F, Veronesi B, Cagnacci A, Modena MG: Effects of progestins on estrogen-induced increase in C-reactive protein in postmenopausal women. Maturitas 2004; 49:315-320.
18 Lakoski SG, Herrington DM: Effects of hormone therapy on C-reactive protein and IL-6 in postmenopausal women: a review article. Climacteric 2005;8:317-326.

19 Stojanovic ND, Kwong P, Byrne DJ, Arnold A, Jagroop IA, Nair D, Press M, Hurel S, Mikhailidis DP, Prelevic GM: The effects of transdermal estradiol alone or with cyclical dydrogesterone on markers of cardiovascular disease risk in postmenopausal women with type 2 diabetes: a pilot study. Angiology 2003;54:391-399.

20 Manning PJ, Allum A, Jones S, Sutherland WH, Williams SM: The effect of hormone replacement therapy on cardiovascular risk factors in type 2 diabetes: a randomized controlled trial. Arch Intern Med 2001;161: 1772-1776.

21 Sites C, L'Hommedieu G, Toth M, Brochu M, Cooper B, Fairhurst P: The effect of hormone replacement therapy on body fat distribution, and insulin sensitivity in menopausal women: a randomized, double blind, placebo controlled trial. J Clin Endocrinol Metab 2005;90:2701-2707.

22 Perera M, Sattar N, Petrie JR, Hillier C, Small M, Connel JM, Lowe GD, Lumbsden MA: The effects of transdermal estradiol in combination with oral norethisterone on lipoproteins, coagulation, and endothelial markers in postmenopausal women with type 2 diabetes: a randomized, placebo-controlled study. J Clin Endocrinol Metab 2001;86: 1140-1143.

-23 Roussel AM, Bureau I, Favier M, Polansky MM, Bryden NA, Anderson RA: Beneficial effects of hormonal replacement therapy on chromium status and glucose and lipid metabolism in postmenopausal women. Maturitas 2002;42:63-69.

24 Chu MC, Cosper P, Nakhuda GS, Lobo RA: A comparison of oral and transdermal shortterm estrogen therapy in postmenopausal women with metabolic syndrome. Fertil Steril 2006;86:1669-1675. 